\title{
Efficacy and Safety of Existing and Emerging Monoclonal Antibody Therapies for Multiple Sclerosis
}

\author{
Gavin Giovannoni \\ Blizard Institute, Barts and The London School of Medicine and Dentistry, Queen Mary University London, UK
}

$\mathrm{T}$ he introduction of monoclonal antibodies for multiple sclerosis (MS) has provided a molecular targeted approach to modify the course of disease. A major advantage of monoclonal antibodies in the treatment of MS is that they are designed to be specific to their target and have very few off-target effects. Monoclonal antibodies have distinct structural characteristics and different targets, and their various mechanisms of action include cross-linking, blocking interactions, induction of signal transduction via receptor binding, complement-dependent cytotoxicity, and antibody-dependent cell-mediated cytotoxicity. Monoclonal antibodies should not therefore be considered a single class of treatments. Natalizumab and alemtuzumab are highly efficacious treatments approved for treating MS, though they tend to be reserved for patients with more active disease. Other monoclonal antibodies in advanced development include ocrelizumab, ofatumumab, anti-CD25 monoclonal antibody, daclizumab and opicinumab (anti-LINGO-1). Screening and monitoring is required to enable the optimal utilisation of all monoclonal antibodies and the benefit-risk profile of each monoclonal antibody needs to be fully considered before use. At present, patients have variable access to effective MS treatments, and this issue is likely to become even more important to address as new therapies become available.

\section{Keywords}

Monoclonal antibodies, multiple sclerosis (MS), alemtuzumab, daclizumab, natalizumab, ocrelizumab, ofatumumab, opicinumab

Disclosure: Gavin Giovannoni has received compensation for serving as a consultant or speaker for, or has received research support from: AbbVie, Bayer Schering Healthcare, Biogen Idec, Canbex, Eisai, Elan, Five Prime Therapeutics, Genzyme, Genentech, GlaxoSmithKline, Ironwood Pharmaceuticals, Merck-Serono, Novartis, Roche, Sanofi-Aventis, Synthon BV, Teva Pharmaceutical Industries, UCB and Vertex Pharmaceuticals. This article involves a review of the literature and did not involve any studies with human or animal subjects performed by any of the authors.

Acknowledgements: Medical writing assistance was provided by Catherine Amey at Touch Medical Media, funded by Roche.

Authorship: All named authors meet the International Committee of Medical Journal Editors (ICMJE) criteria for authorship of this manuscript, take responsibility for the integrity of the work as a whole, and have given final approval to the version to be published.

Open Access: This article is published under the Creative Commons Attribution Noncommercial License, which permits any non-commercial use, distribution, adaptation and reproduction provided the original author(s) and source are given appropriate credit.

Received: 31 May 2016

Accepted: 5 August 2016

Citation: European Neurological Review, 2016;11(2):96-100

Corresponding Author: Gavin Giovannoni, Blizard Institute, Barts and The London School of Medicine and Dentistry, Queen Mary University London, 4 Newark Street, London E1 2AT, UK; Department of Neurology, Royal London Hospital, Barts Health NHS Trust, London, UK. E: g.giovannoni@qmul.ac.uk

Support: The publication of this article was supported by an independent, educational grant provided by Roche. Roche had no influence on the development or content of the article except in reviewing the accuracy of the medical data presented.
The options available for treating multiple sclerosis (MS) have increased substantially over the last two decades. Initial first-line diseasemodifying therapies (DMTs), included intramuscular (IM) interferon (IFN) $\beta-1 a$ (Avonex ${ }^{\circledast}$, Biogen, Cambridge, Massachusetts, US), subcutaneous (SC) IFN $\beta$-1a (Rebif® ${ }^{\circledR}$ EMD Serono, Rockland, Massachusetts, US), SC IFN $\beta-1 \mathrm{~b}$ (Betaferon ${ }^{\circledR}$, Bayer, Leverkusen, Germany; Extavia ${ }^{\circledR}$, Novartis, Basel, Switzerland [2007]) and SC glatiramer acetate [GA] (Copaxone ${ }^{\circledR}$, Teva Neuroscience, Petah Tikva, Israel). Mitoxantrone and later natalizumab, both high efficacy treatments, were generally used second-line. ${ }^{1-7}$ Although moderately efficacious, patient adherence to IFNs and GA was and remains an important challenge despite innovations in the formulation and delivery of these DMTS. ${ }^{89}$ Further, some patients with MS develop neutralising antibodies (NAbs) when treated with IFN- $\beta$, which abrogates the therapeutic efficacy..$^{10}$ Poor adherence to these DMTs has been shown to result in a reduction in efficacy and in worse patient outcomes. ${ }^{11}$

It is common practice in some countries for physicians to prescribe several first-line therapies such as IFN $\beta$-1a or GA before switching to monoclonal antibodies. ${ }^{12}$ However, there is growing evidence that, in addition to the early initiation of treatment after diagnosis, ${ }^{13}$ early treatment optimisation after insufficient response to initial treatment is important to achieve a favourable outcome. ${ }^{14}$ Recently, a new strategy has emerged, 'treating to target,' where the aim is to achieve no evidence of disease activity (NEDA). This composite measure is defined as no relapse activity, no Expanded Disability Status Scale (EDSS) disability progression, and no new magnetic resonance imaging (MRI) lesions (T1 Gd+ and/or active T2 lesions). ${ }^{15-17}$ Confirming NEDA necessitates regular monitoring of relapses, disability and for subclinical activity on MRI. ${ }^{18}$ There is a report from a study of 152 patients indicating that the monoclonal antibody, natalizumab, is associated with a higher proportion of patients achieving NEDA status compared with those reported previously for injectable treatments. ${ }^{19}$ 
Table 1: Summary of the main monoclonal antibody therapies approved or in development for multiple sclerosis

\begin{tabular}{|c|c|c|c|c|}
\hline Agent & Target & Proposed mechanism of action & $\begin{array}{l}\text { Phase of } \\
\text { development }\end{array}$ & Licensed indication \\
\hline Natalizumab & $\begin{array}{l}\alpha 4 \text { subunit of } \alpha 41 \text { and } \\
\alpha 47 \text { integrins }\end{array}$ & $\begin{array}{l}\text { Inhibition of lymphocyte binding to endothelial } \\
\text { receptors, preventing entry into the CNS }\end{array}$ & Approved & $\begin{array}{l}\text { EU: a single therapy for adults with high levels of } \\
\text { disease activity despite IFN or glatiramer acetate } \\
\text { or adults with rapidly evolving severe RRMS } \\
\text { USA: monotherapy for relapsing MS }\end{array}$ \\
\hline Alemtuzumab & $\begin{array}{l}\text { CD52 on lymphocyte } \\
\text { and monocyte cell } \\
\text { surfaces }\end{array}$ & Depletion of CD52+ cells & Approved & $\begin{array}{l}\text { EU: Adult patients with RRMS and active disease } \\
\text { defined by clinical or imaging features } \\
\text { USA: relapsing forms of MS* }\end{array}$ \\
\hline Daclizumab & $\begin{array}{l}\text { CD25 on activated } \\
\text { T-lymphocytes }\end{array}$ & $\begin{array}{l}\text { Antagonizes CD25-mediated signalling blocking } \\
\text { T-cell activation and expansion; expands regulatory } \\
\text { CD56 bright NK cells }\end{array}$ & Approved & $\begin{array}{l}\text { EU: Adult patients with relapsing forms of MS } \\
\text { USA: relapsing forms of MS in patients who have } \\
\text { had an inadequate response to two or more MS } \\
\text { drugs }\end{array}$ \\
\hline Ocrelizumab & CD20 & Depletes CD20+ B cells & Phase III & NA \\
\hline Ofatumumab & CD20 & Inhibits early-stage B lymphocyte activation & Phase II & NA \\
\hline Ustekinumab & $\begin{array}{l}\text { P40 subunit of } \\
\text { IL-12 and IL-23 }\end{array}$ & $\begin{array}{l}\text { Disrupts IL-12- and IL-23-mediated signalling which } \\
\text { would otherwise elicit inflammatory and immune } \\
\text { responses }\end{array}$ & Phase II & NA \\
\hline $\begin{array}{l}\text { Tabalumab } \\
\text { (LY2127399) }\end{array}$ & BAFF & $\begin{array}{l}\text { Counteracts dysregulated BAFF expression which } \\
\text { may contribute to MS via effects on abnormal B } \\
\text { Iymphocyte activation, proliferation, survival, and } \\
\text { Ig secretion }\end{array}$ & Phase II & NA \\
\hline Secukinumab & IL-17A & $\begin{array}{l}\text { Inhibition of the release of pro-inflammatory } \\
\text { cytokines and chemokines. }\end{array}$ & Phase II & NA \\
\hline Vatelizumab & VLA-2 & $\begin{array}{l}\text { Interferes with collagen-binding in areas of } \\
\text { inflammation }\end{array}$ & Phase II & NA \\
\hline GNbAC1 & $\begin{array}{l}\text { Envelope protein of MS- } \\
\text { associated retrovirus }\end{array}$ & Blocks upstream pathophysiology of MS & Phase II & NA \\
\hline Opicinumab & Anti-LINGO-1 & $\begin{array}{l}\text { Binding of the Fab (fragment antibody-binding) } \\
\text { region of the antibody to LINGO-1, and the resulting } \\
\text { complex formation, blocks epitopes in the LINGO-1 } \\
\text { IgG domain that function in oligodendrocyte } \\
\text { differentiation }\end{array}$ & Phase II & NA \\
\hline MEDI-551 & CD19 & $\begin{array}{l}\text { Enhanced antibody-dependent cell-mediated } \\
\text { cytotoxicity }\end{array}$ & Phase II & NA \\
\hline rHIgM22 & Remyelinating antibody & $\begin{array}{l}\text { Inhibits apoptotic signalling and differentiation } \\
\text { through Lyn kinase }\end{array}$ & Phase I & NA \\
\hline VX15/2503 & SEMA4D & Blocks SEMA4D activity & Phase I & NA \\
\hline MOR103 & GM-CSF & Blocks GM-CSF interaction with its receptor & Phase I & NA \\
\hline
\end{tabular}

Monoclonal antibodies are used therapeutically in a variety of medical disciplines including oncology, rheumatology, gastroenterology, dermatology and prevention of transplant rejection. Three monoclonal antibody treatments are currently approved for treating MS, (natalizumab, ${ }^{20-24}$ alemtuzumab25-30 and daclizumab ${ }^{31}$ ). These are high efficacy treatments but tend to be reserved for more active patients, in particular in patients with rapidly-evolving severe MS (Table 1). Other humanised monoclonal antibodies are currently in advanced development (Phase II and III) mainly in the treatment of patients with relapsing-remitting MS (RRMS). These include ocrelizumab, ${ }^{32,33}$ ofatumumab (both anti-CD20), ${ }^{34,35}$ anti-CD25 monoclonal antibody, and opicinumab (anti-LINGO-1). ${ }^{36}$

The anti-CD20 monoclonal antibody, rituximab, ${ }^{37}$ was in development and despite being very effective in phase $\|$ the development programme was terminated due to issues linked to immunogenicity, due to it only being partially humanised, and its imminent patent expiry.
Two further monoclonal antibodies, tocilizumab ${ }^{38,39}$ and eculizumab, ${ }^{40,41}$ are in development for neuromyelitis optica, which although often misdiagnosed as MS has a different pathogenesis. Table 1 gives a summary of the monoclonal antibodies currently in Phases I, II and III.

Monoclonal antibodies have distinct structural characteristics (e.g. chimeric, humanised, fully human) and different targets, including blocking interactions, cross-linking, induction of signal transduction by receptor binding, complement-dependent cytotoxicity, antibodydependent cell-mediated cytotoxicity. These confer various and different mechanisms of action in MS (Table 1).

\section{Monoclonal antibodies and the implications for therapy}

Monoclonal antibodies are potentially advantageous for the treatment of MS in that they are designed to be very specific in terms of their 
Figure 1: Primary endpoint in OPERA I and OPERA II studies - statistically significant reduction in annualised relapse rate compared with IFN $\beta-1 a^{65}$

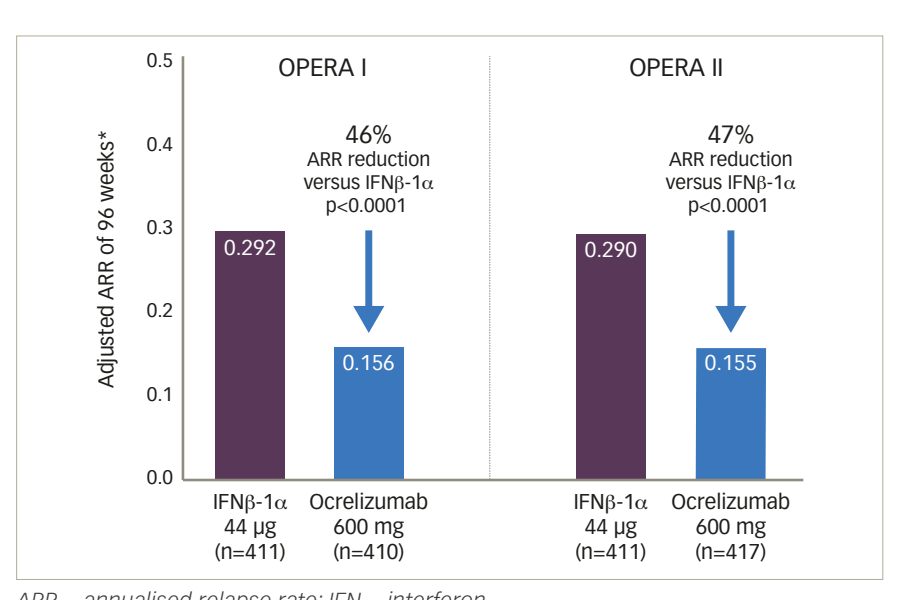

$A R R=$ annualised relapse rate; IFN = interferon

relevant target and unlike small molecules have very few off-target effects. ${ }^{42}$ Many monoclonal antibodies can also be given over an initial short period and then patients do not necessarily need to receive any further doses for 6 months or longer, e.g. ocrelizumab and alemtuzumab. In contrast, the injectable and oral DMTs for MS require long-term, frequent (often daily) administration. ${ }^{7,43,44}$

Monoclonal antibodies for MS cannot be considered a single class of treatments given the multiplicity of targets and wide spectrum of benefit-risk profiles. Immunogenicity profiles and effector functions likewise vary considerably with antibody type. When choosing an appropriate treatment, careful consideration must be made of the many unique characteristics of each monoclonal antibody therapy, especially, rare serious adverse events and uncertainties about long-term safety.

Some monoclonal antibody treatments have serious safety concerns, which may discourage their use in many patients and may limit their use as first-line therapies. ${ }^{45,46}$ Diligent monitoring of patients (for conditions such as John Cunningham virus [JCV]/progressive multifocal leukoencephalopathy [PML] with natalizumab), however, has been shown to reduce the risk of serious adverse events in those receiving monoclonal antibodies. ${ }^{47}$ Certain treatment-related complications may not become apparent until monoclonals are more widely prescribed, as exemplified with natalizumab and the association with PML. Currently a strategy is available to help predict which individual patients may develop PML;4 four major risk factors have been identified: JCV sero-positivity, a high antibody index against JCV, the prior use of immunosuppressants and a treatment duration with natalizumab of 2 years or more. The TYSABRI Outreach: Unified Commitment to Health (TOUCH) Prescribing Program is in place to inform prescribers, infusion centre healthcare providers, and patients about the risk of PML associated with natalizumab, including the increased risk of PML with treatment duration and prior immunosuppressant use. The program also seeks to warn against concurrent use with anti-neoplastic, immunosuppressant, or immunomodulating agents and in patients who are immunocompromised and promote early diagnosis of PML and timely discontinuation of natalizumab in the event of suspected PML.

The benefit-risk profiles of these monoclonal antibody treatments therefore need to be carefully considered and understood before using them. ${ }^{48}$ Further, review of clinical efficacy and safety results are needed as well as consideration that the clinical trials of monoclonal antibodies have been evaluated using different methods and comparators and in different patient populations. The treatment of MS requires a consistent policy to be developed; ${ }^{49}$ unfortunately, patients currently have variable access to effective treatments. This is likely to become an increasingly pressing issue, especially as new therapies become available. Screening and monitoring is required to enable the optimal use of monoclonal antibodies to improve treatment outcomes for patients with MS.

\section{Natalizumab}

In a randomised, double-blind trial, 213 patients with relapsing remitting or relapsing secondary progressive MS to receive $3 \mathrm{mg}$ of intravenous natalizumab/kg of body weight $(n=68), 6 \mathrm{mg} / \mathrm{kg}(n=74)$ or placebo $(n=71)$ every 28 days for 6 months. ${ }^{50}$ The mean number of new lesions was significantly reduced in both natalizumab groups (9.6 per patient in the placebo group versus 0.7 in the group given $3 \mathrm{mg}$ of natalizumab per $\mathrm{kg}(\mathrm{p}<0.001)$ and $1.1 \mathrm{in}$ the $6 \mathrm{mg}$ natalizumab per $\mathrm{kg}$ group $(p<0.001)$. In addition, 27 patients who received placebo relapsed versus 13 and 14 in the $3 \mathrm{mg}$ natalizumab per $\mathrm{kg}$ and $6 \mathrm{mg}$ natalizumab ( $\mathrm{p}=0.02)$. In the randomised, placebo-controlled trial, Natalizumab Safety and Efficacy in Relapsing Remitting Multiple Sclerosis (AFFIRM; $n=942$ ), natalizumab reduced both the risk of the sustained progression of disability and the rate of clinical relapsed in patients with relapsing MS (RMS) versus placebo. ${ }^{51}$ Over 2 years, natalizumab treatment reduced the risk of sustained disability progression by $42 \%$ (hazard ratio, 0.58 ; $95 \%$ confidence interval $[\mathrm{Cl}], 0.43$ to $0.77 ; p<0.001)$ and the rate of clinical relapse at 1 year was reduced by $68 \%(p<0.001)$ versus placebo. Natalizumab also demonstrated a sustained effect in the prevention of new lesion formation in this trial. ${ }^{52}$ Sub-group analysis was performed for patients who had experienced two or more relapses in the prior year and also had at least one gadolinium-enhancing lesion on brain MRI or a significant increase in T2 lesion load when compared with a previous recent MRI. ${ }^{53}$ The Tysabri (natalizumab) Observational Program is an open-label, multinational, 10-year prospective study in clinical practice settings. Interim, 5-year results have confirmed the overall safety profile of natalizumab and the low relapse rate and stabilised disability levels in natalizumab-treated patients with RRMS in clinical practice. ${ }^{54}$

\section{Alemtuzumab}

In the International Campath-1H in Multiple Sclerosis (CAMMS223) trial, in 334 patients with early RRMS, alemtuzumab significantly reduced the rate of sustained accumulation of disability, compared with IFN $\beta$-1a (9.0\% versus $26.2 \%$; hazard ratio, $0.29 ; 95 \% \mathrm{Cl}, 0.16$ to 0.54 ; $p<0.001$ ). In the alemtuzumab group compared with the IFN $\beta$-1a group, adverse events included autoimmunity (thyroid disorders [23\% versus 3\%] and immune thrombocytopenic purpura [3\% versus $1 \%]$ ) and infections $(66 \% \text { versus } 47 \%)^{55}$

Of 334 patients originally randomised in the CAMMS223 trial, 198 participated in the extension phase (151 [68\%] alemtuzumab and 47 [42\%] IFN $\beta$-1a). ${ }^{56}$ At 5 -year follow-up of CAMMS223 clinical trial, alemtuzumab versus IFN $\beta$-1a reduced both the risk of sustained disability accumulation and the rate of relapse by $72 \%$ and $69 \%$, respectively (both $p<0.0001$ ).

In the 2-year, rater-masked, randomised, controlled phase III trial, Comparison of Alemtuzumab and Rebif ${ }^{\circledast}$ Efficacy in Multiple Sclerosis, Study One (CARE-MS I) ( $n=386), 75$ (40\%) patients treated with IFN $\beta$-1a relapsed (122 events) compared with 82 (22\%) patients who were treated alemtuzumab (119 events; rate ratio 0.45 [95\% Cl 0.32-0.63]; p <0.0001). ${ }^{57}$ However, no benefit was observed in respect of disability endpoints. CARE-MS II, was also a 2-year, rater-masked, randomised, controlled phase III trial, with 667 RRMS patients and at least one 
relapse on IFN $\beta$ or GA. ${ }^{58}$ In total, 104 (51\%) patients treated with IFN $\beta$-1a relapsed (201 events), compared with 147 (35\%) patients in the alemtuzumab group (236 events; rate ratio 0.51 [95\% Cl 0.39-0.65]; $\mathrm{p}<0.0001$ ), representing a $49.4 \%$ improvement with alemtuzumab. In addition, 40 (20\%) patients treated with IFN $\beta$-1a had sustained accumulation of disability compared with 54 (13\%) of those treated with alemtuzumab (hazard ratio 0.58 [95\% Cl 0.38-0.87]; $p=0.008$ ). This corresponded to a $42 \%$ improvement in the alemtuzumab group. common adverse events of alemtuzumab include infusion-related reactions, which are generally mild and short-lived, and increased risk of infections following a treatment course..$^{59}$ Potentially very serious side effects may also occur including thyroid disorders, kidney problems and blood clotting problems.

\section{Daclizumab}

Daclizumab high yield process (HYP) demonstrated clinically important effects on disease activity in during 1 year of treatment versus placebo in patients with RRMS in the Daclizumab high-yield process in relapsingremitting multiple sclerosis (SELECT) study.60 Improvements versus placebo were also reported on health-related quality of life ${ }^{61}$ and disease-activity-free status. ${ }^{62}$ five hundred and seventeen (91\%) of 567 patients who completed the SELECT trial entered Daclizumab high-yield process in relapsing-remitting multiple sclerosis (SELECTION), a 52-week extension study which aimed to assess the safety and immunogenicity of extended treatment with daclizumab HYP. ${ }^{63}$ Adverse events and immunogenicity were not increased in the second year of continuous treatment with daclizumab HYP or during treatment washout and reinitiation. In the Efficacy and Safety of BlIB019 (Daclizumab High Yield Process) Versus Interferon $\beta$ 1a in Participants With Relapsing-Remitting Multiple Sclerosis (DECIDE) study, daclizumab has demonstrated superior efficacy compared with IFN $\beta$-1a across several MS outcome measures in RMS patients. ${ }^{31}$ Treatment with daclizumab compared with IFN $\beta$-1a resulted in a $45 \%$ reduction in the annualised relapse rate $(p<0.001)$ although the percentage of patients who relapsed did not differ significantly between the daclizumab and IFN $\beta$ - 1 a group (51\% versus $67 \%$, respectively). There was a $54 \%$ reduction in the number of new/ enlarging T2 hyperintense lesions at week 96 for daclizumab versus IFN $\beta$-1a $(p<0.0001)$. In addition, an increased incidence was seen in the daclizumab-treated group versus IFN $\beta$-1a in serious infections ( $4 \%$ versus $2 \%$ ), serious cutaneous events ( $2 \%$ versus $1 \%$ ), and alanine transaminase (ALT) or aspartate aminotransferase (AST) elevations ( $>5 \mathrm{x}$ upper limit of normal) $6 \%$ versus 3\%. ${ }^{31}$ No treatment-related deaths occurred and there was no evidence of an increased risk of malignancies versus IFN $\beta$-1a. The most common adverse events associated with daclizumab are elevations of liver enzymes and hepatic injury, cutaneous events, infections, gastrointestinal disorders and depression. ${ }^{64}$

\section{Ocrelizumab}

In a phase II, randomised, placebo-controlled, multicentre trial, patients with RRMM were assigned to either placebo, low-dose (600 mg) or highdose (2000 mg) ocrelizumab given as two doses on days 1 and 15, or IM IFN $\beta$-1a (30 $\mu g$ ) once a week. ${ }^{33}$ At 24 weeks, the number of Gd-enhancing lesions was $89 \%$ lower in the $600 \mathrm{mg}$ ocrelizumab group compared with the placebo group ( $95 \% \mathrm{Cl} 68-97 ; \mathrm{p}<0.0001)$, and $96 \%$ lower in the 2000 mg ocrelizumab group (95\% Cl 89-99; $p<0.0001$ ).

OPERA I and II are two identical Phase III, multicentre, randomised, double-blind, double-dummy, parallel-group trials aiming to assess the efficacy and safety of ocrelizumab $(n=821)$ versus IFN $\beta$-1a $(n=835)$ in patients with relapsing forms of MS. ${ }^{65}$ Ocrelizumab significantly reduced annualised relapse rate, the primary endpoint (Figure 1). Another Phase
Figure 2: ORATORIO primary endpoint - confirmed disability progression at 12 weeks $^{66}$

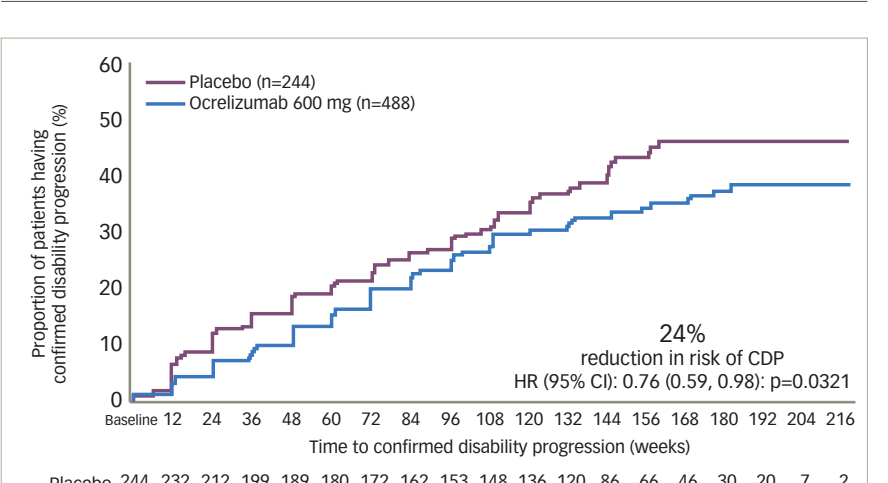

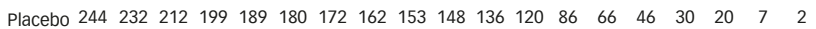
$\begin{array}{lllllllllllllllllllll}\text { Ocrelizumab } 487 & 462 & 460 & 431 & 414 & 391 & 376 & 365 & 338 & 319 & 304 & 281 & 207 & 166 & 136 & 80 & 47 & 20 & 7\end{array}$ $C D P=$ confirmed disability progression; $\mathrm{Cl}=$ confidence interval; $\mathrm{HR}=$ hazard ratio

III trial, ORATORIO, has assessed the efficacy and safety of ocrelizumab versus placebo in patients with primary progressive MS. Initial analysis has revealed that, compared with placebo, ocrelizumab gave a statistically significant reduction in confirmed disability progression at 12 weeks (Figure 2). ${ }^{66}$ A similar reduction was seen in the secondary endpoint of confirmed disability progression at 24-weeks. Overall, the safety profile over the controlled treatment periods for the Phase III trials in RMS and primary progressive MS was favourable in comparison with IFN $\beta$-1a or placebo.

\section{Opicinumab}

Leucine rich repeat and Immunoglobin-like domain-containing protein 1 (LINGO-1) is a cell surface glycoprotein specific to the central nervous system ${ }^{67,68}$ that suppresses oligodendrocyte differentiation and myelination. ${ }^{6970}$ Opicinumab (also known as BIIB033 or anti-LINGO-1) is a potential first-in-class fully human monoclonal antibody that is antagonistic to LINGO-1. Data from a preclinical study in rats suggest that blocking LINGO-1 with opicinumab leads to axonal protection during acute optic nerve injury. ${ }^{36}$ An international phase II study (RENEW) investigated the efficacy of opicinumab in participants with their first episode of acute optic nervitis (ClinicalTrials.gov identifier: NCT01721161). In addition, a phase II study is in progress to evaluate the efficacy, safety and tolerability of opicinumab in patients with active relapsing MS when used concurrently with IFN $\beta-1$ a (ClinicalTrials.gov Identifier: NCT01864148).

\section{Conclusions}

Over the past decade there has been an ongoing tremendous evolution of novel, monoclonal antibody treatment options for MS. However, improved options for the treatment of secondary progressive MS remains an important unmet need. Results for ocrelizumab and other anti-CD20 B cell-depleting monoclonal antibodies for the treatment of relapsing MS have shown promising effects especially on MRI measures of MS disease activity. Results of phase III studies will help determine the place of ocrelizumab in the current armamentarium of MS therapies. Safety issues such as infusion reactions may be mitigated by pre-treatment with corticosteroids in addition to symptomatic management with antihistamines. Post-marketing Risk, Evaluation and Mitigation Strategies are needed so that potential adverse events can be identified and managed early and effectively. ${ }^{71}$ No treatment has as yet been proven to be effective for myelin repair or neuro-regeneration in MS although progress in understanding MS pathology and biotechnological advances will continue to provide hope that this long standing challenge may be met in the future. $\square$ 
1. Derwenskus J, Lublin FD, Future treatment approaches to multiple sclerosis, Handb Clin Neurol, 2014:122:563-77.

Kim W, Zandona ME, Kim SH, Kim HJ, Oral disease-modifyin therapies for multiple sclerosis, I Clin Neurol, 2015:11:9-19.

3. Loleit $\mathrm{V}$, Biberacher $\mathrm{V}$, Hemmer B, Current and future therapies targeting the immune system in multiple sclerosis, Curr Pharm Biotechnol, 2014;15:276-96.

4. Ransohoff RM, Hafler DA, Lucchinetti CF, Multiple sclerosis-a quiet revolution, Nat Rev Neurol, 2015;11:134-42.

5. Sedal L, Wilson IB, MCDonald EA, Current management of relapsing-remitting multiple sclerosis, Intern Med J, 2014;44:950-7.

6. Sorensen PS, New management algorithms in multiple sclerosis, Curr Opin Neurol, 2014;27:246-59.

7. Weinstock-Guttman $B$, An update on new and emerging therapies for relapsing-remitting multiple sclerosis, Am J Manag Care 2013:19(17 Suppl):S343-54.

8. Bruce JM, Lynch SG, Multiple sclerosis: MS treatment adherence--how to keep patients on medication? Nat Rev Neurol, 2011;7:421-2.

9. Wong J, Gomes T, Mamdani M, et al., Adherence to multiple sclerosis disease-modifying therapies in Ontario is low, Can Neurol Sci, 2011;38:429-33

10. Manceau P, Latarche $C$, Pittion S, et al., Neutralizing antibodies and fatigue as predictors of low response to interferon-beta treatment in patients with multiple sclerosis, BMC Neurol, 2014;14:215.

11. Patti F, Optimizing the benefit of multiple sclerosis therapy: the importance of treatment adherence, Patient Prefer Adherence, 2010:4:1-9.

12. Rio J, Comabella M, Montalban X, Multiple sclerosis: current treatment algorithms, Curr Opin Neurol, 2011;24:230-7.

. Tintore M, Early MS treatment, Int MS I, 2007:14:5-10.

14. Ziemssen T, De Stefano N, Pia Sormani M, et al., Optimizing therapy early in multiple sclerosis: An evidence-based view, Mult Scler Relat Disord, 2015:4:460-9.

15. Havrdova E, Galetta S, Hutchinson M, et al., Effect of natalizumab on clinical and radiological disease activity in multiple sclerosis: a retrospective analysis of the Natalizuma Safety and Efficacy in Relapsing-Remitting Multiple Sclerosis (AFFIRM) study, Lancet Neurol, 2009;8:254-60.

16. Giovannoni G, Cook S, Rammohan K, et al., Sustained diseaseactivity-free status in patients with relapsing-remitting multiple sclerosis treated with cladribine tablets in the CLARITY study: a post-hoc and subgroup analysis, Lancet Neurol, 2011:10:329-37.

17. Kieseier BC, Stuve O, A critical appraisal of treatment decisions in multiple sclerosis--old versus new, Nat Rev Neurol, 2011;7:255-62.

18. Ziemssen $\mathrm{T}$, Derfuss $\mathrm{T}$, de Stefano $\mathrm{N}$, et al., Optimizing treatment success in multiple sclerosis, J Neurol, 2016;263:1053-65.

19. Prosperini L, Fanelli F, Pozzilli C, Long-term assessment of No Evidence of Disease Activity with natalizumab in relapsing multiple sclerosis, J Neurol Sci, 2016;364:145-7.

20. Chataway J, Miller DH, Natalizumab therapy for multiple sclerosis, Neurotherapeutics, 2013;10:19-28.

21. Hoepner R, Faissner S, Salmen A, et al., Efficacy and side effects of natalizumab therapy in patients with multiple sclerosis, I Cent Nerv Syst Dis, 2014;6:41-9.

22. Iaffaldano $P$, Lucchese $G$, Trojano $M$, Treating multiple sclerosis with natalizumab, Expert Rev Neurother 2011:11:1683-92.

23. McCormack PL, Natalizumab: a review of its use in the management of relapsing-remitting multiple sclerosis, Drugs, 2013:73:1463-81

24. Pucci E, Giuliani G, Solari A, et al., Natalizumab for relapsing remitting multiple sclerosis, Cochrane Database Syst Rev, 2011:CD007621

25. Coles AJ, Alemtuzumab therapy for multiple sclerosis, Neurotherapeutics, 2013;10:29-33.

26. Coles AJ, Alemtuzumab treatment of multiple sclerosis, Semin Neurol, 2013;33:66-73.

27. Hartung HP, Aktas O, Boyko AN, Alemtuzumab: a new therapy for active relapsing-remitting multiple sclerosis, Mult Scler, 2015;21:22-34

28. Havrdova E, Horakova D, Kovarova I, Alemtuzumab in the treatment of multiple sclerosis: key clinical trial results and considerations for use, Ther Adv Neurol Disord, 2015:8:31-45
29. Jones $D E$, Goldman $M D$, Alemtuzumab for the treatment of relapsing-remitting multiple sclerosis: a review of its clinica pharmacology, efficacy and safety, Expert Rev Clin Immunol 2014;10:1281-91.

30. Ruck T, Bittner S, Wiendl H, Meuth SG, Alemtuzumab in Multiple Sclerosis: Mechanism of Action and Beyond, Int $\mathrm{J} \mathrm{Mol} \mathrm{SCl}$ 2015;16:16414-39.

31. Kappos L, Wiendl H, Selmaj K, et al., Daclizumab HYP versus Interferon Beta-1a in Relapsing Multiple Sclerosis, N Eng/ J Med, 2015;373:1418-28

32. Chaudhuri A, Ocrelizumab in multiple sclerosis: risks and benefits, Lancet, 2012;379:1196-7; author reply 7 .

33. Kappos L, Li D, Calabresi PA, et al., Ocrelizumab in relapsingremitting multiple sclerosis: a phase 2, randomised, placebocontrolled, multicentre trial, Lancet, 2011:378:1779-87.

34. Sorensen PS, Lisby S, Grove R, et al., Safety and efficacy of ofatumumab in relapsing-remitting multiple sclerosis: a phase 2 study, Neurology, 2014:82:573-81.

35. Zhang B, Ofatumumab, mAbs, 2009:1:326-31.

36. Cadavid D, Balcer $\sqcup$, Galetta SL, et al., Axonal Protective Role of LINGO-1 Blockade in the Visual System: Results From a Study in Rats and Designof of a Phase 2 Clinical Trial for BIIB033, a Anti-LINGO-1 Monoclonal Antibody, in Subjects With a First Episode of Acute Optic Neuritis, Presented at: 66 th Annual Meeting of the American Academy of Neurology, 26 April-3 May, Philadelphia, PA, USA, 2014

37. Castillo-Trivino $T$, Braithwaite $D$, Bacchetti P, Waubant $E$, Rituximab in relapsing and progressive forms of multiple sclerosis: a systematic review, PLoS One, 2013:8:e66308.

38. Araki M, Matsuoka T, Miyamoto K, et al., Efficacy of the anti-IL-6 receptor antibody tocilizumab in neuromyelitis optica: a pilot study, Neurology, 2014;82:1302-6.

39. Lauenstein AS, Stettner M, Kieseier BC, Lensch E, Treating neuromyelitis optica with the interleukin-6 receptor antagonis tocilizumab, BMJ Case Rep, 2014;2014.

40. Paul $F$, Hope for a rare disease: eculizumab in neuromyelitis optica, Lancet Neurol, 2013;12:529-31.

41. Pittock SJ, Lennon VA, McKeon A, et al., Eculizumab in AQP4 IgG-positive relapsing neuromyelitis optica spectrum disorders: an open-label pilot study, Lancet Neurol, 2013;12:554-62.

42. Gensicke $\mathrm{H}$, Leppert D, Yaldizli O, et al., Monoclonal antibodies and recombinant immunoglobulins for the treatment of multiple sclerosis, CNS Drugs, 2012;26:11-37.

43. Cross AH, Naismith RT, Established and novel diseasemodifying treatments in multiple sclerosis, I Intern Med 2014:275:350-63.

44. Kieseier $\mathrm{BC}$, Wiendl $\mathrm{H}$, Hartung $\mathrm{HP}$, Stuve $\mathrm{O}$, The future of multiple sclerosis therapy, Pharmacological Research, 2009;60:207-11.

45. D'Amico E, Caserta C, Patti F, Monoclonal antibody therapy in multiple sclerosis: critical appraisal and new perspectives, Expert Rev Neurother, 2015;15:251-68.

46. Knier B, Hemmer B, Korn T, Novel monoclonal antibodies for therapy of multiple sclerosis, Expert Opin Biol Ther 2014;14:503-13.

47. Kornek B, An update on the use of natalizumab in the treatment of multiple sclerosis: appropriate patient selection and special considerations, Patient Prefer Adherence, 2015;9:675-84.

48. Fontoura $\mathrm{P}, \mathrm{Monoclonal}$ antibody therapy in multiple sclerosis: Paradigm shifts and emerging challenges, mAbs, 2010;2:670-81

49. Kobelt G, Berg J, Lindgren P, et al., Costs and quality of life of patients with multiple sclerosis in Europe, $J$ Neurol Neurosurg Psychiatry, 2006;77:918-26.

50. Miller DH, Khan OA, Sheremata WA et al A controlled tria of natalizumab for relapsing multiple sclerosis, N Eng J Med, 2003;348:15-23.

51. Polman $\mathrm{CH}, \mathrm{O}^{\prime} \mathrm{C}$ onnor PW, Havrdova E, et al., A randomized placebo-controlled trial of natalizumab for relapsing multiple sclerosis, N Eng J Med, 2006;354:899-910.

52. Miller DH, Soon D, Fernando KT, et al., MRI outcomes in a placebo-controlled trial of natalizumab in relapsing MS, Neurology, 2007;68:1390-401.

53. Hutchinson M, Kappos L, Calabresi PA, et al., The efficacy of natalizumab in patients with relapsing multiple sclerosis: subgroup analyses of AFFIRM and SENTINEL, J Neurol, 2009;256:405-15
54. Butzkueven H, Kappos L, Pellegrini F, et al., Efficacy and safety of natalizumab in multiple sclerosis: interim observational programme results, I Neurol Neurosurg Psychiatry. 2014:85:1190-7.

55. Coles AJ, Compston DA, Selmaj KW, et al., Alemtuzumab vs. interferon beta-1a in early multiple sclerosis, N Eng J Med 2008;359:1786-801

56. Coles AJ, Fox E, Vladic A, et al., Alemtuzumab more effective than interferon beta-1a at 5-year follow-up of CAMMS223 clinical trial, Neurology, 2012;78:1069-78.

57. Cohen JA, Coles AJ, Arnold DL, et al., Alemtuzumab versus interferon beta $1 \mathrm{a}$ as first-line treatment for patients with relapsing-remitting multiple sclerosis: a randomised controlled phase 3 trial, Lancet, 2012;380:1819-28.

58. Coles AJ, Twyman CL, Arnold DL, et al., Alemtuzumab for patients with relapsing multiple sclerosis after diseasemodifying therapy: a randomised controlled phase 3 trial, Lancet, 2012:380:1829-39.

59. European Medicines Agency, LEMTRADA Summary of Product Characteristics, 2013. Available from: www.ema.europa.eu/ docs/en_GB/document_library/EPAR__Product_Information/ human/003718/WC500150521.pdf (accessed date 15 August 2016)

60. Gold R, Giovannoni G, Selmaj K, et al., Daclizumab high-yield process in relapsing-remitting multiple sclerosis (SELECT): a randomised, double-blind, placebo-controlled trial, Lancet 2013;381:2167-75.

61. Phillips $\mathrm{G}, \mathrm{Guo} \mathrm{S}$, Bender R, et al., Assessing the impact of multiple sclerosis disease activity and daclizumab HYP treatment on patient-reported outcomes: Results from the SELECT trial, Mult Scler Relat Disord, 2016;6:66-72.

62. Havrdova E, Giovannoni G, Stefoski D, et al., Disease-activityfree status in patients with relapsing-remitting multiple sclerosis treated with daclizumab high-yield process in the SELECT study, Mult Scler, 2014;20:464-70.

63. Giovannoni G, Gold R, Selmaj K, et al., Daclizumab high-yield process in relapsing-remitting multiple sclerosis (SELECTION): a multicentre, randomised, double-blind extension trial, Lancet Neurol, 2014;13:472-81.

64. European Medicines Agency, Committee for Medicinal Products for Human Use (CHMP) Summary of Opinion. Zinbryta, 2016. Available from: http://www.ema.europa.eu/ema/index jsp?curl=pages/medicines/human/medicines/003862/smops/ Positive/human smop 000970.jsp\&mid=WC0b01ac058001d127 (accessed date: 15 August 2016)

65. Hauser SL, Comi GC, Hartung HP, et al., on behalf of the OPERA I and II clinical investigators, Efficacy and safety of ocrelizumab in relapsing multiple sclerosis - results of the interferonbeta-1 1 -controlled, double-blind, Phase III OPERA I and II studies, Presented at: Congress of the European Committee for Treatment and Research in Multiple Sclerosis (ECTRIMS), Barcelona, Spain, 9 October 2015

66. Montalban X, Hemmer B, Rammohan K, et al., on behalf of the ORATORIO Clinical Investigators. Efficacy and safety of ocrelizumab in primary progressive multiple sclerosis - results of the placebo-controlled, double-blind, Phase III ORATORIO study, Presented at: Congress of the European Committee for Treatment and Research in Multiple Sclerosis (ECTRIMS), Barcelona, Spain, 10 October 2015.

67. Carim-Todd L, Escarceller M, Estivill X, Sumoy L, LRRN6A/ LERN1 (leucine-rich repeat neuronal protein 1), a novel gene with enriched expression in limbic system and neocortex, Eur $\rfloor$ Neurosci, 2003:18:3167-82.

68. Mi S, Lee X, Shao Z, et al., LINGO-1 is a component of the Nogo66 receptor/p75 signaling complex, Nat Neurosci, 2004:7:221-8.

69. Lee X Yang Z Shao Z et al. NGF regulates the expression of axonal LINGO-1 to inhibit oligodendrocyte differentiation and myelination, J Neurosci, 2007:27:220-5.

70. Mi S, Miller RH, Lee X, et al., LINGO-1 negatively regulates myelination by oligodendrocytes, Nat Neurosci, 2005;8:745-51.

71. Hersh CM, Cohen JA, Alemtuzumab for the treatment of relapsing-remitting multiple sclerosis, Immunotherapy, 2014;6:249-59

72. Lycke J, Monoclonal antibody therapies for the treatment of relapsing-remitting multiple sclerosis: differentiating mechanisms and clinical outcomes, Ther Adv Neurol Disord 2015;8:274-93. 